\title{
NOTE ON \\ - TRANSLITERATION - \\ AND DATES
}

THE SYSTEM OF TRANSLITERATION USED HERE RENDERS CONsonants according to the system adopted by the International Journal of Middle East Studies, but omits diacritical marks, with the exception of the hamza ('), the ayn ( ${ }^{\circ}$ ), and Â and â for long alif. Vowels are rendered to reflect the sound in English that most closely approximates modern Persian pronunciation. Established words and names in English are Anglicized. Personal names are rendered in accordance with the transliteration rules outlined here, except when cited in sources in European languages. All translations are by the author unless otherwise stated.

In the text, dates are all in the Common Era unless they refer directly to Persian texts. In the notes and bibliography, dates are given in the Islamic solar (shamsi) calendar current in Iran and are followed by the corresponding date in the Common Era separated by a slash. Dates prior to the official adoption of the solar calendar in Iran (legislated by the Majles on I I Farvardin 1304/3 I March 1925) are given in the Islamic lunar (gamari) calendar followed by A. H. (anno Hegirae) and the corresponding date in the Common Era. On 20 Esfand I354/10 March 1976 an "imperial calendar" was introduced that begins with the foundation of the Achaemenian Empire in 559 B.C.E.; hence the Persian New Year I355/1976 corresponds to 2535. Although the new measure was reversed on I I Shahrivar 1357/2 September 1978 in the wake of the revolution, most works published in Iran during that period bear the imperial date. Those dates are followed here by the more familiar Islamic shamsi dates in square brackets and the corresponding date in the Common Era. 
THIS PAGE INTENTIONALLY LEFT BLANK 